\title{
BREEDING SYSTEMS AND FLORAL BIOLOGY IN THE GENUS BRIZA
}

\author{
BRIAN G. MURRAY* \\ Deportment of Botony, The University, Whiteknights, Reading RG6 2AS
}

Received 12.i.74

\begin{abstract}
SUMMARY
Floral morphology is shown to be closely correlated with the type of breeding system in the genus Briza L. (Gramineae). The outbreeding species have large anthers and stigmas that are well exerted at anthesis whereas in the inbreeding species anthers and stigmas are small and the flowers are frequently cleistogamous. Self-incompatibility in $B$. media is controlled by two genes, both with multiple alleles. Identity at both loci is necessary for pollen inhibition. Pollen control is gametophytic, incompatible pollen tubes are inhibited on the stigmatic surface. Unilateral incompatibility occurs in crosses between self-incompatible and self-compatible species. Self-compatible pollen is inhibited on self-incompatible stigmas but the reciprocal shows no inhibition.
\end{abstract}

\section{INTRODUCTION}

BREEDING systems in plants show a remarkable diversity. In Angiosperms self-incompatibility is the most widespread device promoting cross-fertilisation (East, 1940; Fryxell, 1957; Crowe, 1964). Though all self-incompatibility systems serve the same purpose the genetic basis varies. Control may be brought about by polygenic systems or supergenes; gene expression may be sporophytic or gametophytic and the site of action at the ovary, in the style or on the stigmatic surface.

Usually the genetic basis of self-incompatibility is alike in closely related groups. Previous studies of intraspecific incompatibility in the Gramineae (Lundquist, 1956, 1961a, 1962a, 1969; Hayman, 1956) have shown that there are two loci that control the incompatibility reaction. However, Hayward and Wright (1971) working on Lolium perenne did not find any clear pattern of segregation amongst $F_{1}$ progenies and were not able to draw any precise conclusions about the genetics of incompatibility in this species. This work casts some doubts on the universality of the two locus systems of self-incompatibility in the Gramineae.

Within genera, within species and even within a single population it is not uncommon to find self-compatibility and self-incompatibility co-existing within the group. In the long term, a permanent change from outbreeding to enforced inbreeding is accompanied by changes in floral morphology. These changes are particularly striking in insect-pollinated flowers and examples can be found in genera such as Passiflora (Lewis, 1966), Clarkia (Moore and Lewis, 1965), Gilia (Grant, 1964) and many others. Windpollinated flowers do not show such obvious adaptations though their evolution from outbreeding to inbreeding is also accompanied by subtle

* Present address: Department of Botany and Biochemistry, Westfield College, London NW3 7ST. 
changes in floral morphology. Amonst the grasses such changes have been reported in Bromus (Harlan, 1945; Stebbins, 1957), Elymus (Snyder, 1950), Festuca and Poa (Stebbing, 1970).

Apart from the correlated changes in breeding system and floral morphology within species, there are additional breeding barriers between species. Pollen-style reactions in interspecific crosses between self-compatible and self-incompatible species can be used to "date" the relative age of a self-compatible species. Lewis and Crowe (1958) proposed that there are two types of self-compatible species. The first type, the Sc species, are considered to be recent mutants in which the stylar activity is unimpaired but self pollen is not inhibited since it has lost its incompatibility specificity. The second type, the SG species, are thought to be long established selfcompatible species in which neither pollen nor style is active but their pollen is inhibited on the style of self-incompatible species. Thus recent mutants to self-compatibility can be distinguished from long-established self-compatible species on the basis of their pollen behaviour in inter-specific crosses with selfincompatible species. Though there are exceptions to this hypothesis it has been found to be applicable to a large number of species in many families of Angiosperms.

This paper is an attempt to show the variety in floral structure and to elucidate the genetic control of intra- and inter-specific incompatibility in the genus Briza L.

\section{Materials AND Methods}

Plants used in this study were either collected from natural populations growing near Reading or grown from seed supplied by Botanic gardens and research institutes. Studies of the floral structures of some species were made on herbarium specimens at the Royal Botanic Gardens, Kew (K) or the Reading University Herbarium (RNG).

For the study of the incompatibility system of $B$. media an $\mathrm{F}_{1}$ progeny was produced by controlled pollinations of plants from different populations. As pollen tube growth was found to be closely correlated with seed-set this was used to assess compatible and incompatible pollinations. All pollinations were carried out using the petri dish technique as described by Lundquist $(1961 b)$. Pollen tubes in stigmatic tissue were observed by means of the callose fluorochrome reaction (Lalouette, 1967).

TABLE 1

Breeding systems in Briza

Self-incompatible species

B. media $\mathrm{L}$.

B. australis Prokudin

B. elatior Sibth. \& Sm.
Self-compatible species

$B$. minor $\mathrm{L}$.

$B$. maxima $\mathrm{L}$.

B. poaemorpha (Presl) Henrard

B. stricta (Hook. \& Arn.) Steudel

$B$. triloba Nees

B. subaristata Lamarck

*B. lilloi Parodi

*B. rufa (Presl) Steudel

*B. lindmanii Ekman

*B. macrostachya (Presl) Steudel

*B. uniolae (Nees) Nees ex Steudel

*B. bidentata Roseng., Arr. et Izag.

* Only herbarium specimens studied. 


\section{Results}

\section{(i) Floral morphology}

The outbreeding and inbreeding species" of Briza are listed in table 1. The outbreeding species have three large anthers $(2 \cdot 2-2.5 \mathrm{~mm}$ long), produce copious pollen and have large feathery stigmas; all mechanisms to aid crosspollination. In the inbreeding species there appears to be a trend towards smaller anthers and stigmas, a reduction in the number of anthers and consequently a considerable reduction in pollen production (fig. 1).
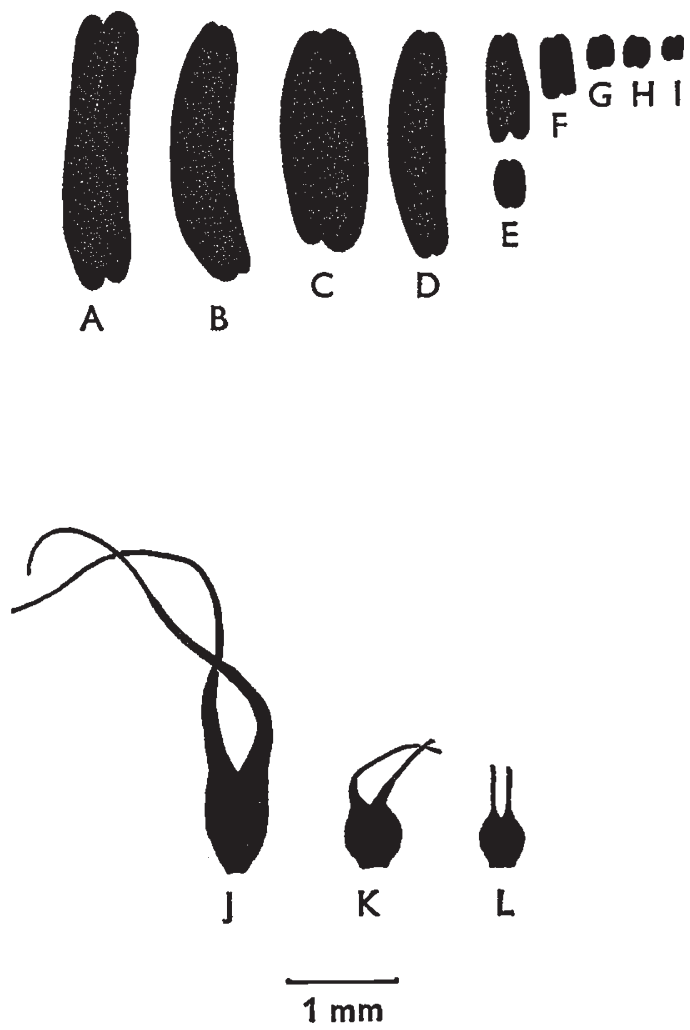

FIg. 1.-Diagram to show the variation in anther and stigma size in species of Briza.

Anthers: A, B. media; B, B. australis; C, B. elatior; D, B. maxima; E, B. uniolae; F, B. minor; $\mathrm{G}, B$. stricta; $\mathrm{H}, B$. triloba; I, B. poaemorpha.

Stigmas: J, B. media; K, B. minor; L, B. poaemorpha.

The European inbreeding species, $B$. minor and B. maxima, are chasmogamous but have relatively small anthers and stigmas when compared with the outbreeders. Filament length and stigma size are also reduced in these species.

All the South American species appear to be inbreeding and cleistogamy is a common feature of this group. B. poaemorpha and $B$. lilloi only have cleistogamous flowers. Here a single small anther $(0.2-0.3 \mathrm{~mm}$ long) is borne between the much reduced styles onto which the pollen is directly shed. Other species have both cleistogamous and chasmogamous flowers. 
In this group there may be either three or one anther (1.5-1.3 $\mathrm{mm}$ long) in the chasmogamous flowers but in the cleistogamous flowers there is only a single small anther $(0 \cdot 2-0 \cdot 5 \mathrm{~mm}$ long). B. rufa, B. lindmanii and $B$. macrostachya have three anthers in the chasmogamous flowers and one in the cleistogamous flowers. $B$. uniolae and $B$. bidentata have only a single anther in both types of flowers.

There is little variation in pollen size between species. For example $B$. media, B. maxima, B. minor and $B$. uniolae all have pollen grains of approximately the same diameter and in $B$. uniolae both the large and small anthers contain pollen of the same size.

(ii) Intra-specific incompatibility in B. media

The mating behaviour of an $F_{1}$ progeny was analysed in a $19 \times 19$ diallel and the results are shown in fig. 2. They show firstly that the $F_{1}$ plants, like

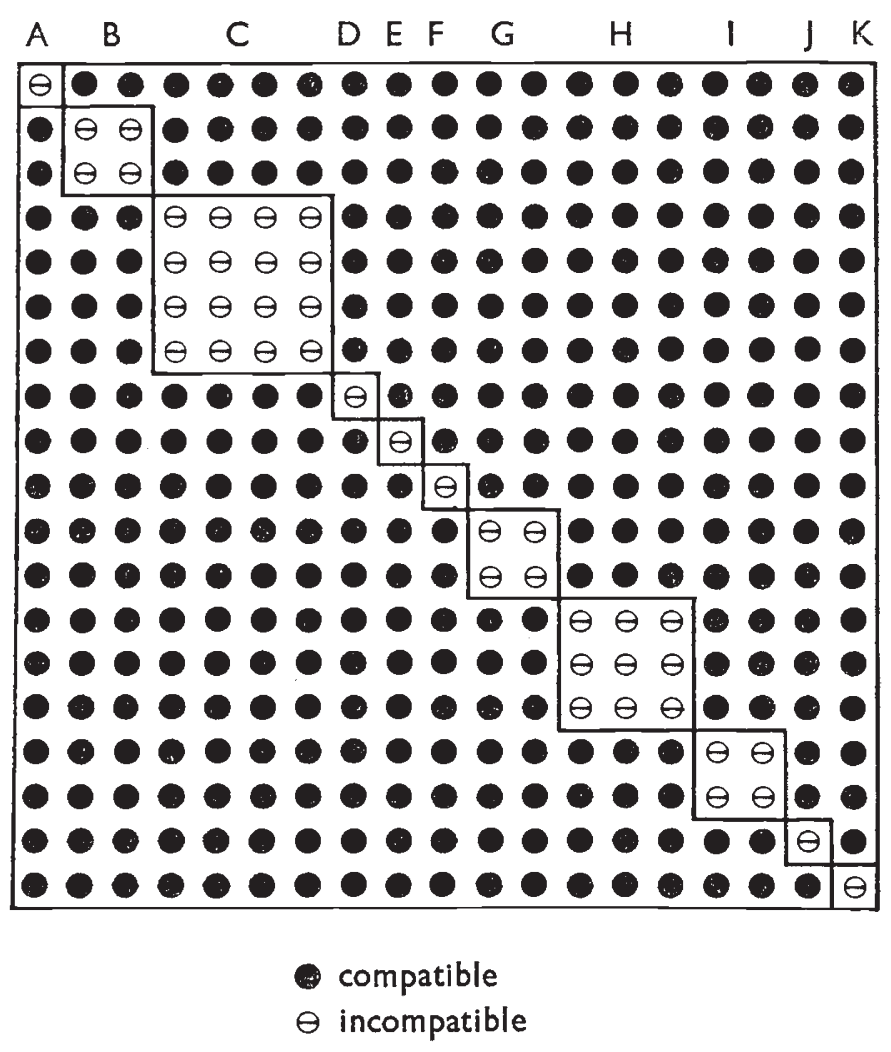

Fig. 2.-The results of intercrossing $19 F_{1}$ plants of Briza media arranged into 11 intraincompatible, inter-compatible breeding groups $(\mathrm{A}-\mathrm{K})$.

the parents, were completely self-incompatible. Secondly, the $19 \mathrm{~F}_{\mathbf{1}}$ plants can be arranged into 11 breeding groups which are all inter-compatible but intra-incompatible.

With 11 breeding groups more than one locus controlling the incompatibility specificities must be postulated, identity at both loci being necessary 
for pollen inhibition. Also, the parental plants must be heterozygous at both of the two proposed loci, $\mathrm{S}$ and $\mathrm{Z}$, since all breeding groups were intercompatible and there were no reciprocal differences in pollen germination as would be expected if the parents had alleles in common. For example, if the parental genotypes were $S_{12} Z_{12}$ and $S_{13} Z_{24}$ there would be 12 breeding groups but certain crosses between the $F_{1}$ plants would give reciprocal differences. $\$ S_{13} Z_{22} \times{ }_{0} S_{13} Z_{12}$ would be compatible but the reciprocal would be incompatible. It is therefore, proposed that the two parental genotypes are $S_{12} Z_{12}$ and $S_{34} Z_{34}$ as a cross of this type would best fit the results obtained.

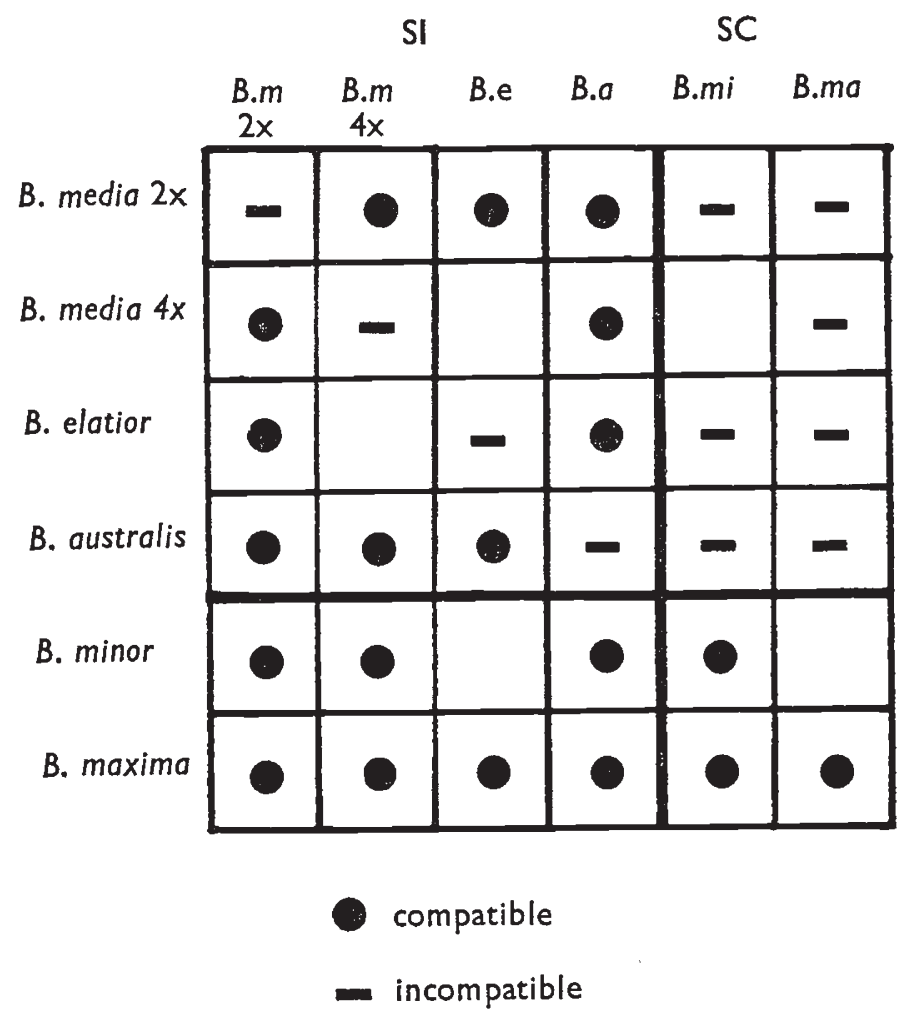

Fig. 3.-Compatibility relationships between some species of Briza.

The absence of reciprocal differences in these crosses is an indication of gametophytic control of the pollen specificity. This is further indicated by the differential behaviour of the pollen in certain crosses. For example, in compatible crosses on stigmas of the same genotype, 100 per cent pollen germination was observed in some crosses but only approximately 50 per cent of the pollen-germinated in other crosses with different male parents. Were the control sporophytic all pollen tubes would react in the same way on the same type of style.

\section{(iii) Inter-specific incompatibility}

The results of the inter-specific crosses show that the pollen of the selfcompatible species of Briza is inhibited on the stigma of the self-incompatible species. Figure 3 shows, firstly, that crosses between self-incompatible 
species like $B$. media and $B$. elatior are compatible. Secondly, that crosses between self-compatible species like $B$. minor and $B$. maxima are compatible. Thirdly, that crosses where the self-compatible species is the female parent and the self-incompatible species is the male parent were also compatible.

Diploid and tetraploid races of $B$. media behaved in a comparable manner with regard to pollen germination and growth. However, in crosses between the chromosome races seed-set was approximately five times greater when the diploid was used as the male parent than vice versa.

In all incompatible crosses the site of inhibition of pollen tube growth was on the stigmatic surface and is therefore the same in both inter- and intraspecific incompatibility.

\section{Discussion}

The self-incompatibility mechanism in $B$. media is particularly strong. Beddows (1931) in a report on seed setting in a number of species of grasses states that $B$. media sets fewer seed on selfing than any of the other species that he examined. In this study seed setting on selfing was non-existent and in the controlled pollinations for the analysis of the $F_{1}$ progeny there was a complete absence of pollen tube growth in any of the self-pollinated plants.

Lundquist (1956 et seq.) and Hayman (1956) have both proposed that incompatibility in the Gramineae is controlled by two genes both with multiple alleles. No linkage has been detected between these two loci thus this type of system is fractionally more efficient as a random cross-breeding mechanism than a single gene system (Lewis, 1966). The data from B. media fit in very well with these previously studied examples of self-incompatibility in the Gramineae, the strength of the incompatibility reaction is probably responsible for the clear-cut results obtained from the analysis of the $F_{1}$ progeny. Thus the genetic basis of incompatibility in Briza appears to be similar to that of all the other species of grasses studied with the possible exception of Lolium perenne.

The two locus system of incompatibility as found in the grasses is thought to have arisen by duplication of an original single locus (Lundquist, $1954,1962 b$ ). Evidence to support this theory comes indirectly from the study of the effect of polyploidy on self-incompatibility in higher plants. In Dicotyledons autopolyploidy commonly results in self-compatibility in plants with a gametophytic system of incompatibility due to dominance and competition between $S$ alleles in the diploid pollen (Lewis, 1947; Sampson, 1960). Monocotyledons appear to show a complete lack of interaction between incompatibility alleles and this may have allowed this system based on duplication to develop in the Gramineae. Annerstedt and Lundquist (1967) have shown that incompatibility in Tradescantia paludosa is controlled by a typical gametophytic system. However, all tetraploids both natural and artificial, were completely self-incompatible. Collins (1961) and Sagawa (1958), working with Ananas comosus and Lilium longiflorum respectively, have also shown that polyploids of these two self-incompatible species do not show any self-fertility. Tetraploid races of $B$. media also retain their self-incompatibility mechanism. These examples lend support to the idea that dominance and competitive interaction do not occur between $S$ alleles in Monocotyledons. This may also explain the apparent absence of sporophytic incompatibility in the Monocotyledons since this involves the development of dominance relationships between $S$ alleles. 
The results of the inter-specific crosses show that unilateral incompatibility occurs between self-incompatible and self-compatible species of the genus Briza. The self-compatible species would appear to be of the SC type and are therefore not of recent origin. This idea is supported by the adaptations shown by the flowers of these species to self-pollination. Anther size and therefore pollen production is reduced, filament lengths decrease and stigmas become smaller and less feathery-all obvious adaptations to self-pollination and inbreeding.

This study has extended the range of incompatibility systems to which Lewis and Crowe's rule can be applied and provides further evidence for the universality of unilateral inhibition in all types of self-incompatibility system. As Pandey (1969) has suggested unilateral incompatibility serves two purposes. Firstly, it prevents self-compatibility alleles from establishing themselves in self-incompatible species. This preserves their outbreeding habit and eliminates the risk of inbreeding depression. Secondly, it may also protect the reproductive capacity of a species by the prevention of inviable, infertile or poorly adapted hybrids being produced.

Acknowledgments.-I would like to thank Dr Leslie K. Crowe for her help and encouragement throughout the course of this work. A postgraduate studentship from the University of Reading Research Board is also gratefully acknowledged.

\section{REFERENGES}

ANNERSTEDT, I., AND LUNDQUIST, A. 1967. Genetics of self-incompatibility in Tradescantia paludosa. Hereditas, 58, 13-30.

BEDDOWs, A. R. 1931. Seed setting and flowering in various grasses. Bull. Welsh Pl. Breed. Stn., H12.

colisiss, J. L. 1961. The Pineapple: Botany, Cultivation and Utilisation. Interscience Publishers Inc., New York.

CROWE, L. x. 1964. The evolution of outbreeding in plants. I. The Angiosperms. Heredity, $19,435-457$.

EAST, E. M. 1940. The distribution of self-sterility in the flowering plants. Proc. Am. Phil. Soc., 82, 449-518.

PRYXELI, P. A. 1957. Mode of reproduction of higher plants. Biol. Rev., 23, 135-233.

GRANT, v. 1964. The biological composition of a taxonomic species in Gilia. Adv. Genet., 12, $281-328$.

HARLAN, J. R. 1945. Cleistogamy and chasmogamy in Bromus carinatus Hook. \& Arn. Am. $\mathcal{F}$. Bot., 32, 66-72.

hayman, D. L. 1956. The genetic control of incompatibility in Phalaris coerulescens Desf. Aust. F. Biol. Sci., 9, 321-331.

HAYWARD, M. D., AND WRIGHT, A. J. 1971. The genetic control of incompatibility in Lolium perenne L. Genetica, 42, 414-421.

LALOUETTE, J. A. 1967. Growth of grass pollen tubes exhibited by callose fluorochrome reaction. Grana palynol., 7, 601-603.

LEWIS, D. 1947. Competition and dominance of incompatibility alleles in diploid pollen. Heredity, 1, 85-108.

LEWIS, D. 1966. The genetic integration of breeding systems. In Reproductive Biology and Taxonomy of Vascular Plants (J. G. Hawkes, ed). Pergamon Press, Oxford.

LEWIS, D., AND CROWE, L. K. 1958. Unilateral interspecific incompatibility in flowering plants. Heredity, 12, 233-256.

LUNDQUTS, A. 1954. Studies on self-sterility in rye, Secale cereale L. Hereditas, 40, 278-294.

LUNDQUIST, A. 1956. Self-incompatibility in rye. I. Genetic control in the diploid. Hereditas, $42,293-348$.

LUNDQUIST, A. 1961a. Self-incompatibility in Festuca pratensis Huds. Hereditas, 47, 542-562.

LUNDQUIST, A. 1961b. A rapid method for the analysis of incompatibilities in grasses. Hereditas, 47, 705-707. 
LUNDQUist, A. 1962a. Self-incompatibility in diploid Hordeum bulbosum L. Hereditas, 48, 138-152.

LUNDQUisT, A. 1962 $b$. The nature of the two loci incompatibility system in grasses. I. The hypothesis of a duplicative origin. Hereditas, 48, 153-168.

LUNDQUIST, A. 1969. Self-incompatibility in Dactylis glomerata L. Hereditas, 61, 353-360. MOORE, D. M., AND LEWIs, H. 1965 . The evolution of self-pollination in Clarkia xantiana. Evolution, 19, 104-114.

PANDEY, K. K. 1969. Elements of the $S$ gene complex. V. Interspecific cross-compatibility relationships and the theory of the evolution of the $S$ complex. Genetica, 40, 447-474.

SAGaWA, y. 1958. The production of polyploid easter lilies. I. Triploids. F. Hered., 49, 194-198.

SAMPSON, D. R. 1960. A hypotheiss of gene interaction at the $S$ locus in self-incompatibility systems in Angiosperms. Am. Nat., 94, 283-292.

SNYDER, L. A. 1950. Morphological variability and hybrid development in Elymus glaucus. Am. F. Bot., 37, 628-636.

STEBBINS, G. L. 1957. Self-fertilisation and population variability in the higher plants. Am. Nat., 91, 337-354.

STEBBINS, G. L. 1970. Adaptive radiation of reproductive characteristics in Angiosperms. I. Pollination mechanisms. Ann. Rev. Ecol. Syst., 1, 307-326. 